\title{
Electrodeposition of Composite $\mathrm{Ni}-\mathrm{TiO}_{2}$ Coatings from Aqueous Acetate Baths
}

\begin{abstract}
KRZYSZTOF MECH
In this paper, results concerning electrochemical deposition of $\mathrm{Ni}^{-\mathrm{TiO}_{2}}$ composite coatings are presented. The influence of electrode potential, concentration of $\mathrm{TiO}_{2}$ in the electrolyte, as well as the influence of magnetohydrodynamic effect (MHD) on deposition rate, composition, current efficiency, structure, surface states, and coatings surface morphology is described. Electrochemical studies were preceded by thermodynamic analysis of the system. In addition, the electrokinetic potential $(\mathrm{ZP})$ of $\mathrm{TiO}_{2}$ particles in applied electrolyte was determined. Electrodeposited composites contained up to $2.15 \mathrm{wt}$. pct of $\mathrm{TiO}_{2}$. Depending on the applied electrolysis conditions, the current efficiency recorded up to $31.7 \mathrm{pct}$ for $B=0 \mathrm{~T}$ and up to 34.2 for $B=1 T$. Electrochemical studies as well as further material characterizations indicated the strong influence of the magnetic field on processes taking place at the electrode surface. Several results indicated that the synthesis process is accompanied by precipitation of nickel hydroxides and nickel hydrides as well as by hydrogen evolution reaction (HER). The obtained coatings were also characterized in order to determine their photoelectrochemical properties.
\end{abstract}

https://doi.org/10.1007/s11661-019-05325-7

(c) The Author(s) 2019

\section{INTRODUCTION}

RESEARCH on the development of new, efficient, and environmentally friendly solar energy conversion systems has been conducted for many years. The main limitations of such systems are related to the catalytic properties of the applied materials. ${ }^{[1]}$ One of the most interesting and widely studied processes is the conversion of solar energy and its storage based on photochemical hydrogen generation. ${ }^{[2]}$ Hydrogen possesses a low molecular weight and high value of combustion energy. In addition, hydrogen combustionresults in water formation, making it the most environmentally friendly available energy carrier. The location of nickel on the $\Delta H_{\mathrm{Me}-\mathrm{H}}-\log \left(i_{0}\right)$ dependence as well as the properties of specially photosensitized and modified $\mathrm{TiO}_{2},{ }^{[3,4]}$ and its resistance to photo corrosion, semiconducting properties as well as its efficiency of UV-Vis absorption allow for the assumption that a combination of these materials may allow for the synthesis of composites of the required properties suitable for photocatalytic water splitting. Common routes concerning the design of materials for hydrogen generation by water

KRZYSZTOF MECH is with the AGH University of Science and Technology, Academic Centre for Materials and Nanotechnology, Al. A. Mickiewicza 30, 30-059 Krakow, Poland. Contact e-mail: kmech@agh.edu.pl

Manuscript submitted March 20, 2019.

Article published online June 25, 2019 splitting are focused on platinum group metal (PGM) alloys, ${ }^{[5-8]}$ or the synthesis of new PGM-free alloys, ${ }^{[9,10]}$ semiconductors, ${ }^{[11,12]}$ or metal-semiconductor composite materials. ${ }^{[13]}$ In the literature, there are also many reports concerning the application of $\mathrm{TiO}_{2}$-based heterostructures of increased charge carrier separation for this purpose. ${ }^{[14-16]}$ The photocatalytic hydrogen generation in metal-semiconductor systems consists of two parallel processes. In the cathodic one, $\mathrm{H}^{+}$ions are reduced to $\mathrm{H}_{2}$ while in the anodic one, under UV light oxidation, water molecules are oxidized. The process can proceed on semiconductors of band gap larger than $1.23 \mathrm{eV}$ corresponding to the water splitting potential. The valence band of $\mathrm{TiO}_{2}$ is more positive than $\mathrm{O}_{2} / \mathrm{H}_{2} \mathrm{O}$ redox potential, and its conducting band is more electronegative than the $\mathrm{H}^{+} / \mathrm{H}_{2}$ redox potential. In addition, $\mathrm{TiO}_{2}$ is highly resistant to photocorrosion under UV-Vis radiation as well as to reactions taking place on its surface making it the most suitable candidate for these kinds of purposes. ${ }^{[17]}$

The properties of electrochemically synthesized $\mathrm{Ni}-\mathrm{TiO}_{2}$ have been investigated most thoroughly in terms of photoelectrochemical properties by de Tacconi et al. ${ }^{[18,19]}$ The $\mathrm{Ni}-\mathrm{TiO}_{2}$ composite has many other potential applications including selective methanation of $\mathrm{CO}{ }^{[20]}$ selective oxidation of chloronitrobenzene to chloraniline, ${ }^{[21]}$ hydrogen generation by photoelectrocatalytic glucose reformation, ${ }^{[22]}$ and photoreduction of $\mathrm{CO}_{2}$ to methane. ${ }^{[23]}$

One of the methods of synthesis of the $\mathrm{Ni}-\mathrm{TiO}_{2}$ materials is electrodeposition. Mohajeri et al. reported 
results concerning successful pulse potential deposition of $\mathrm{Ni}-\mathrm{TiO}_{2}$ composites of wide composition range from Watts bath. ${ }^{[2]}$ Thiemig and Bund obtained $\mathrm{Ni}^{-} \mathrm{TiO}_{2}$ coatings by galvanostatic deposition from sulfamate baths. ${ }^{[23]}$ Sulfamate bath was also applied by Stankovic et al. for the analysis of the influence of $\mathrm{TiO}_{2}$ concentration in the electrolyte on the surface properties of deposited $\mathrm{Ni}^{-} \mathrm{TiO}_{2}$ coatings. Synthesized coatings contained up to ca. 4 wt. pct of $\mathrm{TiO}_{2}$ at very high concentration of $\mathrm{TiO}_{2}$ in the electrolyte amounting to $80 \mathrm{~g} / \mathrm{L}^{[24]}$

A number of papers devoted to the synthesis of $\mathrm{Ni}-\mathrm{TiO}_{2}$ composites in recent years show that investigations focused on the analysis of effects influencing transport kinetics in electrochemical aqueous systems containing nickel ions and $\mathrm{TiO}_{2}$ particles are still of great importance. ${ }^{[24-26]}$

The literature indicates possibilities for modification of the properties of materials synthesized through electrochemical methods by the presence of a magnetohydrodynamic (MHD) effect generated by the Lorentz force, causing an additional convection in the electrolyte. Modification of the magnetic field configuration may influence the composition, structure and morphology of alloys and semiconductors. ${ }^{[10,27-30]}$ Lorentz force acts on ions as well as diamagnetic particles moving in the electromagnetic field if the lines of electric field crossing magnetic field ones. Interaction between disturbed electric field and magnetic field result in generation of Lorentz force which in turn is responsible for magnetohydrodynamic effect (MHD). It can be found in the study of Feng et al. that as the result of magnetic field action in near electrode area numerous eddy vortices are located causing additional convection. ${ }^{[31]}$ The presence of the above-mentioned eddy vortices may also positively influence the desorption of gas products formed during cathodic electrode polarization from the electrode surface ${ }^{[32]}$ as well as improve dispersion of particles in the volume of the electrolyte. Results of MHD action may be compared to the effects of electrolyte stirring. Additional mixing in turn increases the gradients of electrochemically active species and reduces the thickness of diffusion layer, which may influence grain size of deposited material. ${ }^{[33]}$

The main objective of the performed studies was to analyze the influence of working electrode potential, concentration of $\mathrm{TiO}_{2}$ particles in the electrolyte as well as value of magnetic field induction vector value $(B)$ on composition, structure, surface properties, and morphology of the synthesized coatings.

The approach based on magnetic field application to synthesis of $\mathrm{Ni}^{-\mathrm{TiO}_{2}}$ composite materials applied and presented in the current study is novel and not described in the literature. Studies conducted indicated possibilities of magnetic field-controlled synthesis of composite $\mathrm{Ni}-\mathrm{TiO}_{2}$ coatings from electrolytes containing acetate nickel complexes for the first time. In the literature so far, there are no reports concerning results of electrogravimetric studies under magnetic field, which provide clear evidence of MHD effect on synthesis of $\mathrm{Ni}^{-\mathrm{TiO}_{2}}$ coatings.

\section{EXPERIMENT DETAILS}

Electrolytes were prepared by dissolution of analytic grade $0.1 \mathrm{M} \mathrm{NiSO}_{4}$ (Aldrich) and acetic acid $\left(\mathrm{C}_{2} \mathrm{H}_{4} \mathrm{O}_{2}\right.$, 99.5 pct, Avantor Materials) in deionized water, and the $\mathrm{pH}$ value was adjusted to 3 by the addition of $\mathrm{NaOH}$ (Avantor Materials). Colloid electrolytes were prepared by the addition of 0 to $10 \mathrm{~g} / \mathrm{L}$ of $\mathrm{TiO}_{2}$ powder [Evonic P25: anatase $(80$ pct $)$, rutile $(20$ pct $)]$.

The electrokinetic potential $(\mathrm{ZP})$ of the $\mathrm{TiO}_{2}$ particles was measured using a Malvern Zetasizer, NANO ZS (Malvern Instruments Ltd.) apparatus equipped with a He-Ne $(\lambda=633 \mathrm{~nm})$ laser. The ZP was determined based on average of three measurements. Before measurement, colloidal electrolytes were dispersed in the presence of ultrasounds for 2 hours. Measurements were performed at room temperature stabilized for 120 seconds.

Thermodynamic calculations were performed using Medusa/Hydra software. ${ }^{[34]}$

Electrochemical tests were performed by means of a BioLogic SP-200 potentiostat/galvanostat. For electrogravimetric tests, the potentiostat was equipped with a Seiko (QCM922A) electrochemical quartz crystal microbalance (EQCM). In electrogravimetric tests, the WE (working electrode) was gold-sputtered quartz crystal $\left(\mathrm{S}=0.25 \mathrm{~cm}^{2}\right)$. The WE surface was placed perpendicular to the cell bottom. The electrolyte volume in electrochemical tests was kept at the same level. Electrodeposition of composites was performed onto a copper sheet $\left(\mathrm{A}=3.14 \mathrm{~cm}^{2}\right)$. Just before electrodeposition, the electrodes were etched in a mixture of $\mathrm{HNO}_{3}$ (96 pct, Avantor Materials), $\mathrm{CH}_{3} \mathrm{COOH}$ (99.5 pct, Aldrich), and $\mathrm{H}_{3} \mathrm{PO}_{4}$ (85 pct, Avantor Materials) with a volume ratio of $1: 1: 1$. As reference electrode, a Leakless $\mathrm{Ag} / \mathrm{AgCl}$ electrode was applied $(0.214 \mathrm{~V} v s$ NHE). All electrochemical tests as well as electrodeposition were performed at room temperature.

XRD (X-ray diffraction) analysis was performed be means of a Panalytical Empyrean diffractometer equipped with a $\mathrm{Cu}$ anode $(40 \mathrm{kV}, 40 \mathrm{~mA})$. Spectra were registered in an angle range of $2 \theta=20$ to $60 \mathrm{deg}$ in step intervals of $0.0263 \mathrm{deg}$ and at a scan rate of $0.5 \mathrm{deg} /$ min.

Chemical composition was analyzed using a WD-XRF (Wavelength Dispersive X-ray Fluorescence) Rigaku Primini II spectrofluorimeter. Elemental analysis was performed for $A=3.14 \mathrm{~cm}^{2}$. During measurement, the sample was rotated.

A Quanta 3D 200i scanning electron microscope was used for characterization of morphology of electrodeposited composite coatings. Due to the high roughness factor, observations were performed at a magnification of $2.5 \mathrm{k}$.

The XPS analyses were carried out in a PHI Versa Probe II Scanning XPS system using monochromatic Al $\mathrm{K} \alpha(1486.6 \mathrm{eV}) \mathrm{X}$-rays focused onto a $100 \mu \mathrm{m}$ spot and scanned over an area of $400 \mu \mathrm{m} \times 400 \mu \mathrm{m}$. The photoelectron take-off angle was $45^{\circ}$, and the pass energy in the analyzer was set to $46.95 \mathrm{eV}$ to obtain high-energy resolution spectra for the $\mathrm{Ti} 2 p, \mathrm{Ni} 2 p_{3 / 2}, \mathrm{C} 1 s$, and $\mathrm{O} 1 s$ regions. A dual-beam charge compensation with $7 \mathrm{eV}$ 
$\mathrm{Ar}^{+}$ions and $1 \mathrm{eV}$ electrons were used to maintain a constant sample surface potential regardless of the sample conductivity. All the XPS spectra were charge referenced to non-functionalized, saturated carbon (C-C) $\mathrm{C} 1 s$ peak at $284.8 \mathrm{eV}$. The operating pressure in the analytic chamber was less than $3 \times 10^{-9}$ mbar. Deconvolution of spectra was carried out using PHI MultiPak software (v.9.7.0.1). The spectrum background was subtracted using the Shirley method.

Magnetic field was generated by a ER-2505 electromagnet (RadioPAN, Poland), and a magnetic field induction vector of $B=1 T$ was oriented in parallel direction vs working electrode surface.

Photocurrent activity measurements were performed by means of a diode of $375 \mathrm{~nm}$, and with $140 \mathrm{~mW}$ applied from a power supply (Instytut Fotonowy) controlled by a RIGOL DG4062 generator in pulse mode. The applied pulse duration was 2.5 seconds, and the interruption time was 7.5 seconds.

\section{RESULTS AND DISCUSSION}

This research was started from the thermodynamic analysis of the $\mathrm{Ni}^{2+}-\mathrm{Ac}^{-}-\mathrm{H}_{2} \mathrm{O}$ system (Figure 1). The calculated dependences allowed for the determination of $\mathrm{pH}$ and ligand concentration range corresponding to thermodynamic stability of electrochemically active nickel complexes. Reactions taken into account in thermodynamic calculations with equilibrium constants are presented in Table I. The obtained thermodynamic results indicate that in the applied electrolyte at a $\mathrm{pH}$ of 3 , nickel ions are complexed to form $\left[\mathrm{Ni}\left(\mathrm{CH}_{3} \mathrm{COO}\right)\right]^{+}$ (42 pct), $\left[\mathrm{Ni}\left(\mathrm{CH}_{3} \mathrm{COO}\right)_{2}\right]^{0}(8 \mathrm{pct})$, and $\left[\mathrm{Ni}\left(\mathrm{H}_{2} \mathrm{O}\right)_{6}\right]^{2+}$ $(50 \mathrm{pct})$ complexes. The determined electrokinetic potential (ZP) value for the $\mathrm{TiO}_{2}$ particles in the electrolyte amounted to $-3.83 \mathrm{mV}$, indicating its high susceptibility for coagulation.

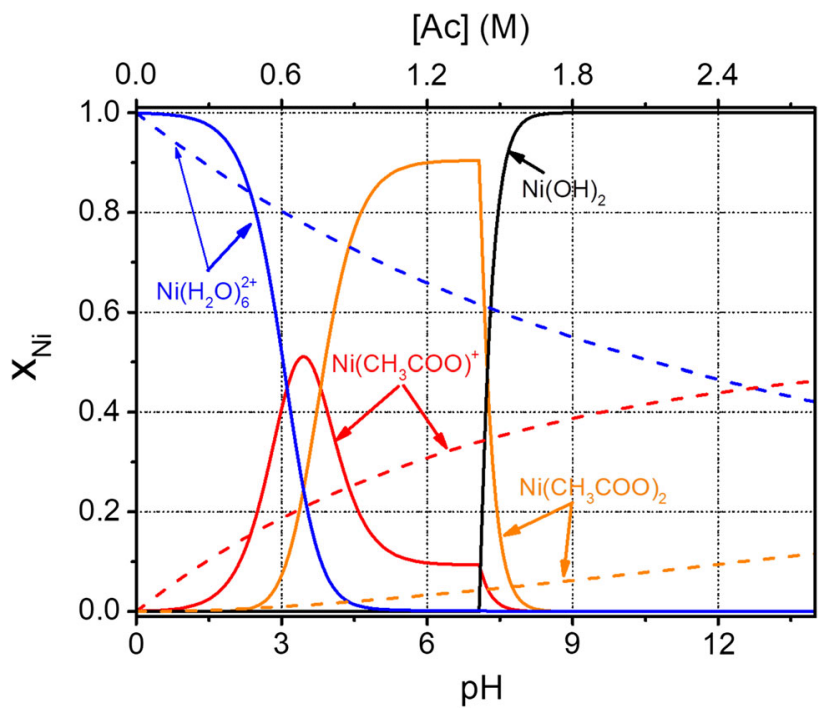

Fig. 1-Distribution diagrams for investigated $\mathrm{Ni}^{2+}-\mathrm{Ac}^{-}-\mathrm{H}_{2} \mathrm{O}$ system: (solid line- $\mathrm{pH}$ dependence, dashed line-ligand concentration dependence).
Figure 2 presents DPV (Differential Pulse Voltammetry) curves recorded in a $\mathrm{TiO}_{2}$-free electrolyte. In voltammograms, there are visible changes of cathodic current density related to the reduction of nickel complexes. Electrogravimetric studies performed in this system show the course of reduction reaction in the same potential range as was previously reported. ${ }^{[38]}$ Based on the current density changes at $E=-1.2 \mathrm{~V}$ for several values of the magnetic field induction vector (B) (Figures 2(a) through (c)), the $i=\zeta\left(v^{1 / 2}\right)$ dependence enabling determination of diffusion coefficients based on Berzins-Delahay Eq. [1] shown in (Figure 2(d)) was plotted. ${ }^{[39]}$

$$
i=-3.6733 \times 10^{5} \cdot z^{\frac{3}{2}} \cdot v^{\frac{1}{2}} \cdot D_{j}^{\frac{1}{2}} \cdot[j],
$$

where $i$ is the cathodic current density $\left(\mathrm{A} \mathrm{cm}^{-2}\right), z$ is the number of electrons consumed in electrode reaction, $v$ is the sweep rate $\left(\mathrm{V} \mathrm{s}^{-1}\right), D_{\mathrm{j}}$ is the diffusion coefficient $\left(\mathrm{cm}^{2} \mathrm{~s}^{-1}\right)$, and $[j]$ is the concentration of several complexes in the electrolyte $\left(\mathrm{mol} \mathrm{cm}^{-3}\right)$. Analysis of the influence of $\mathrm{B}$ on the values of the diffusion coefficient indicated that the magnetohydrodynamic effect generated by the external magnetic field influences the processes of transport of electroactive species to the electrode surface. The observed changes of diffusion coefficients under several conditions ranged from $D=1.13 \times 10^{-6} \quad \mathrm{~cm}^{2} / \mathrm{s} \quad(B=0 \quad T) \quad$ to $D=1.86 \times 10^{-6} \mathrm{~cm}^{2} / \mathrm{s}(1 \mathrm{~T})$. An increase of diffusion coefficients with the increasing magnetic field induction vector clearly indicates significant influence of magnetic field on the species transport kinetics.

Figure 3 presents DPV curves recorded in electrolytes of different $\mathrm{TiO}_{2}$ concentrations and values of $B=0$, 0.5 , and $1 T$. Voltammograms were recorded at a sweep rate of $40 \mathrm{mV} / \mathrm{s}$. Independent of $B$ value, the observed differences in current density were slight, but changes in the cathodic current resulting from the presence of the magnetic field were observable confirming that the magnetic field influences the kinetics of electrode processes. A similar effect was generated by an increase of $\mathrm{TiO}_{2}$ concentration in the electrolyte, but visible changes in cathodic current in this case probably resulted from

Table I. Reactions Considered in Calculations of the Distribution Diagrams in Several Systems with Equilibrium Constants $(T=298 \mathrm{~K})$

\begin{tabular}{lllr}
\hline Ligand & \multicolumn{1}{c}{ Reaction } & \multicolumn{1}{c}{$\log \mathrm{K}$} & Ref. \\
\hline $\mathrm{Ac}^{-}$ & $\mathrm{H}^{+}+\mathrm{Ac}^{-} \rightarrow \mathrm{H}(\mathrm{Ac})$ & 4.757 & 35 \\
& $\mathrm{Ni}^{2+}+\mathrm{Ac}^{-} \rightarrow \mathrm{Ni}(\mathrm{Ac})^{+}$ & 1.37 & \\
& $\mathrm{Ni}^{2+}+2 \mathrm{Ac}^{-} \rightarrow \mathrm{Ni}(\mathrm{Ac})_{2}$ & 2.1 & \\
$\mathrm{H}_{2} \mathrm{O}$ & $\mathrm{Ni}^{2+}+2 \mathrm{OH}^{-} \rightarrow \mathrm{Ni}(\mathrm{OH})_{2}$ & 7.99 & 36 \\
& $\mathrm{Ni}^{2+}+3 \mathrm{OH}^{-} \rightarrow \mathrm{Ni}(\mathrm{OH})_{3}^{-}$ & 12.3 & 37 \\
& $\mathrm{Ni}^{2+}+4 \mathrm{OH}^{-} \rightarrow \mathrm{Ni}(\mathrm{OH})_{4}^{2-}$ & 9 & \\
& $2 \mathrm{Ni}^{2+}+\mathrm{OH}^{-} \rightarrow \mathrm{Ni}(\mathrm{OH})^{3+}$ & 4.2 & \\
$4 \mathrm{Ni}^{2+}+4 \mathrm{OH}^{-} \rightarrow \mathrm{Ni}(\mathrm{OH})_{4}^{4+}$ & 26.1 & \\
& $\mathrm{Ni}^{2+}+\mathrm{OH}^{-} \rightarrow \mathrm{Ni}(\mathrm{OH})^{+}$ & 4.5 & \\
& $\mathrm{Ni}^{2+}+2 \mathrm{OH}^{-} \rightarrow \mathrm{Ni}(\mathrm{OH})_{2}(c)$ & 17.5 & \\
& $\mathrm{Ni}^{2+}+\mathrm{H}_{2} \mathrm{O}^{-} \rightarrow \mathrm{H}^{+}+\mathrm{NiO}(c)$ & -12.67 & 36 \\
\hline
\end{tabular}




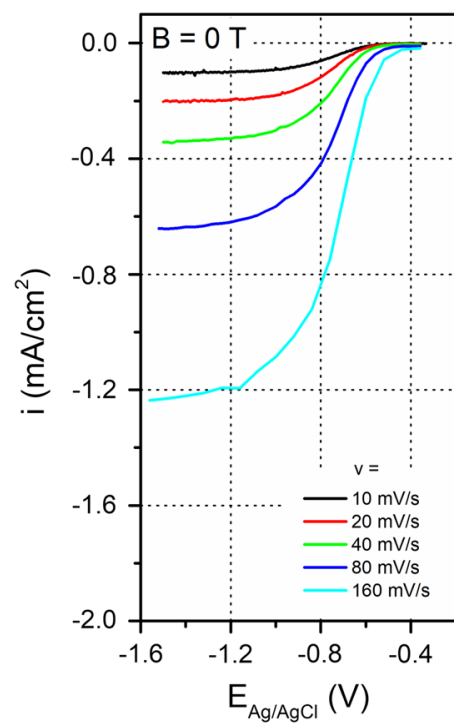

(a)

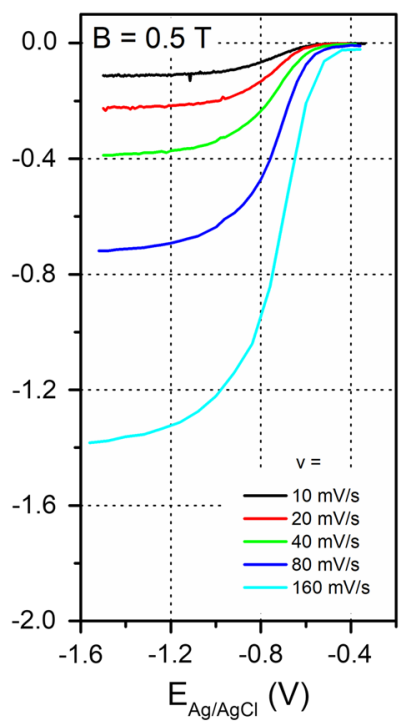

(b)

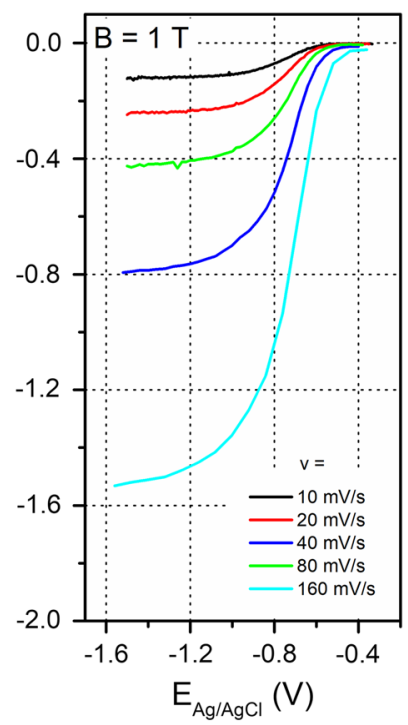

(c)

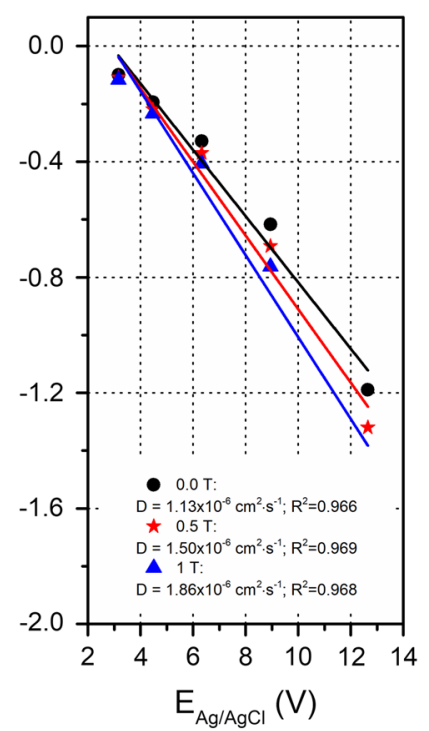

(d)

Fig. 2-DPV curves recorded at different sweep rates at magnetic field induction vectors of $(a) 0 T,(b) 0.5 T,(c) 1 T$, and $(d) i\left(v^{0.5}\right)$ dependence for $i$ at $\mathrm{E}=-1.2 \mathrm{~V}\left(0 \mathrm{~g} / \mathrm{L} \mathrm{TiO}_{2}\right)$.

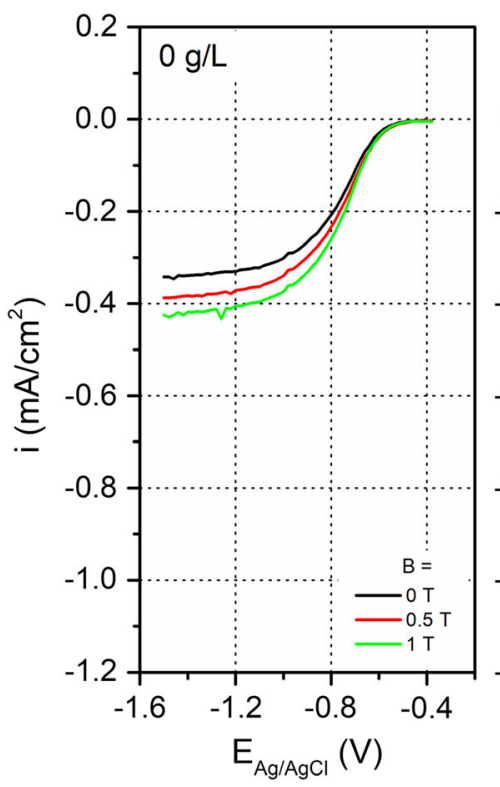

(a)

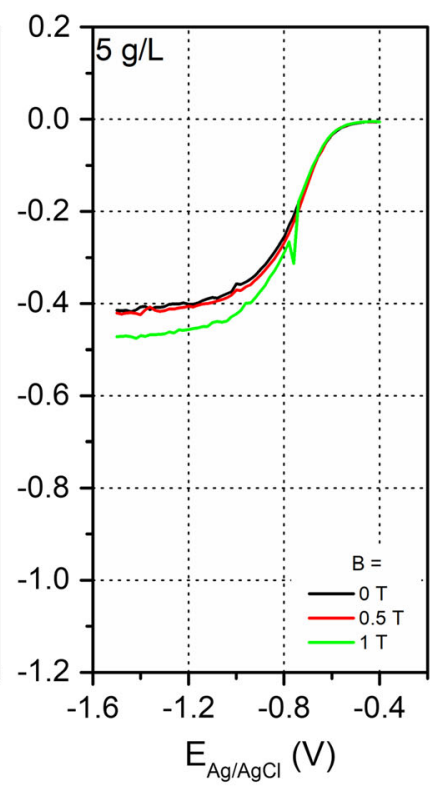

(b)

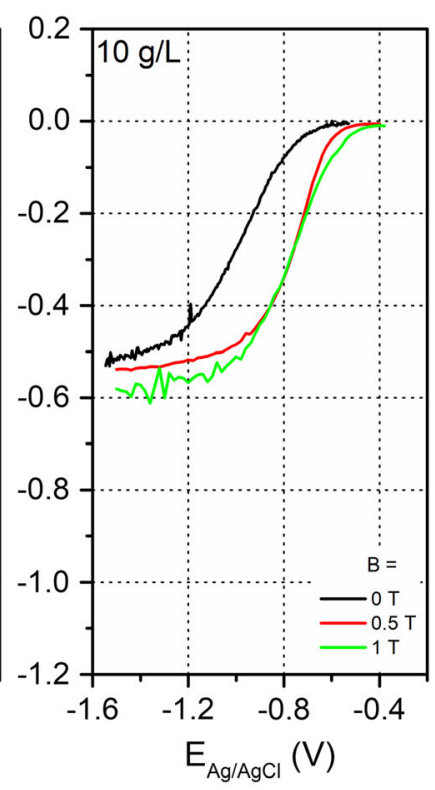

(c)

Fig. 3-DPV curves registered at different $B$ values and concentrations of $\mathrm{TiO}_{2}$ in the electrolyte of $(a) 0 \mathrm{~g} / \mathrm{L},(b) 5 \mathrm{~g} / \mathrm{L}$, and $(c) 10 \mathrm{~g} / \mathrm{L}(v=40$ $\mathrm{mV} / \mathrm{s}$ ).

the influence of $\mathrm{TiO}_{2}$ on the kinetics of the electrode reaction related to HER.

In Figure 4, there are visible current-time transient curves with corresponding electrogravimetric ones recorded during potentiostatic deposition of composites at potentials of $E=-1.2 \mathrm{~V}, E=-1.3 \mathrm{~V}$, and $E=-1.4 \mathrm{~V}$ for 60 seconds. Electrolysis was conducted at magnetic fields of $B=0,0.5$, and $1 T$. Regardless of electrolyte composition as well as $B$ value, the strong influence of the working electrode potential on the rate of electrode reactions was indicated. Similar to DPV curves (Figure 3), current-time transient characteristics as well as electrogravimetric ones (Figure 4) clearly indicated the influence of the magnetic field as well as the concentration of $\mathrm{TiO}_{2}$ in the electrolyte on the kinetics of electrode reactions. In the registered current-time transient curves recorded mainly for $E=-1.3 \mathrm{~V}$ and $E=-1.4 \mathrm{~V}$, there were observed sudden changes in the cathodic current densities which are related to HER. As seen in Figure 4, 

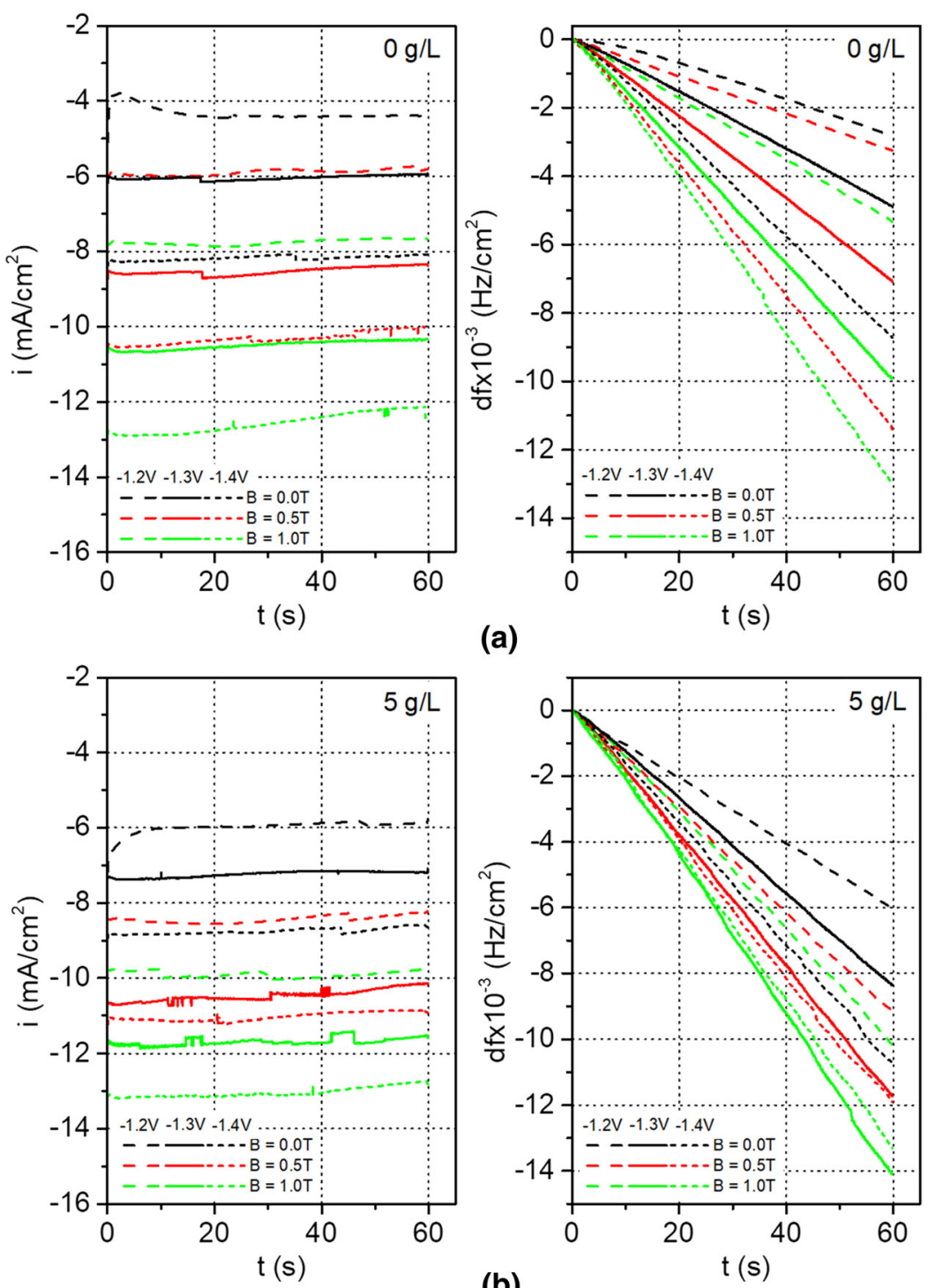

(a)

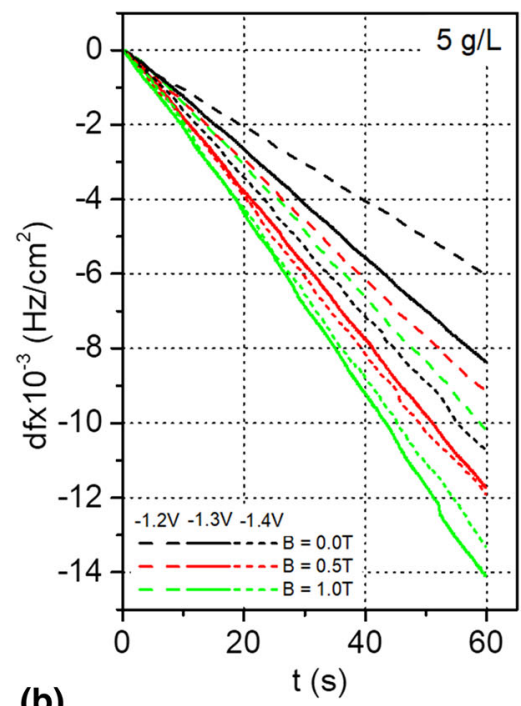

(b)
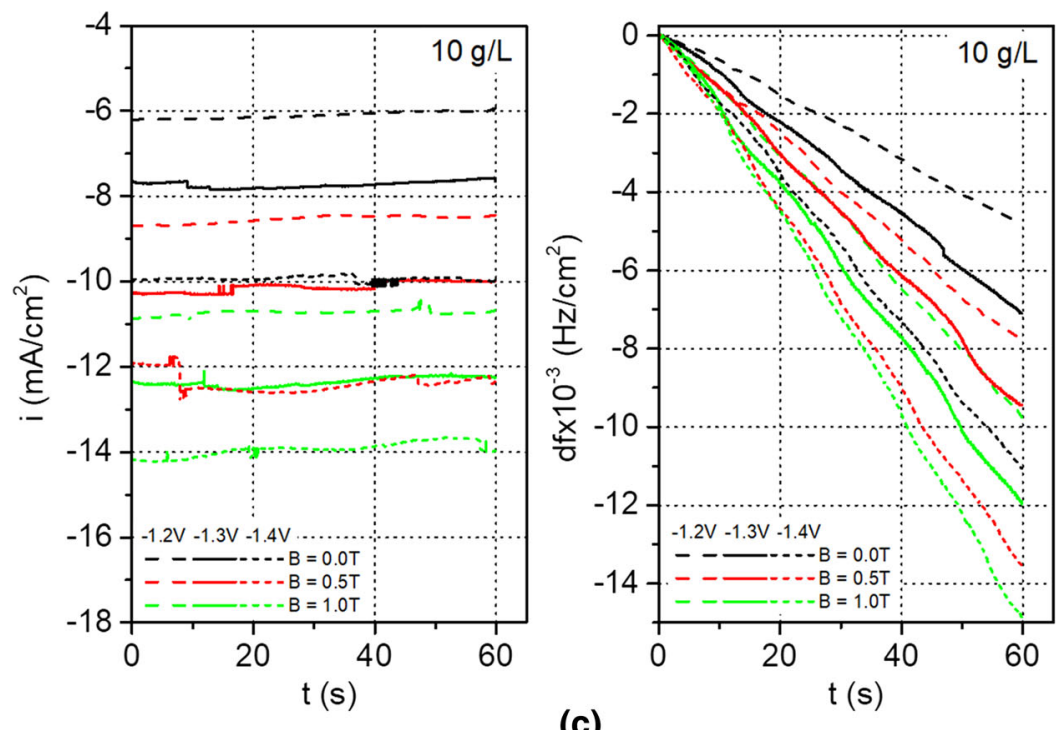

(c)

Fig. 4 - Current-time transient curves with corresponding electrogravimetric ones recorded during electrolysis performed in electrolytes of different concentrations of $\mathrm{TiO}_{2}:(a) 0 \mathrm{~g} / \mathrm{L},(b) 5 \mathrm{~g} / \mathrm{L},(c) 10 \mathrm{~g} / \mathrm{L}$, at different working electrode potentials $(E=-1.2,-1.3,-1.4 \mathrm{~V})$ and values of $B(B=0,0.5,1 T)$. 
electrogravimetric curves provide clear evidence of the influence of magnetic field on kinetics of electrode reactions resulting in the formation of coatings and that reactions are diffusion controlled. An increase of magnetic field induction vector value results in change of kinetics of mass transport through increase of gradient of electrochemically active species in the surface area of the near electrode. The effect in turn results in the increased rate of deposition which is indicated by the increase of changes in quartz crystal electrode oscillations.

Figure 5 presents cyclic voltammograms with corresponding quartz crystal resonator frequency changes recorded as follows: $E=-0.3 \mathrm{~V} \rightarrow E=-1.6 \mathrm{~V} \rightarrow$ $E=0.7 \mathrm{~V} \rightarrow E=-0.3 \mathrm{~V}$ at a sweep rate of $v=20$ $\mathrm{mV} / \mathrm{s}$. In recorded voltammograms, a clear peak corresponding to the reduction of acetate nickel complexes has not been observed, whereas in the anodic branch two peaks related to oxidation of phases formed during the cathodic sweep are visible. As was described in previous study, peak $\mathrm{C}$ is related to the oxidation of the $\beta$-Ni phase (hydrogen rich), while peak D is related to the oxidation of $\alpha$-Ni phase (of low hydrogen concentration) ${ }^{[38]}$ An increase of $\mathrm{TiO}_{2}$ concentration up to $5 \mathrm{~g} /$ $\mathrm{L}$ resulted in significant changes in cathodic current density observed in the HER range. Further increase of $\mathrm{TiO}_{2}$ concentration up to $10 \mathrm{~g} / \mathrm{L}$ resulted in less significant changes. Current density changes in the cathodic range did not clearly indicate the effects of several electrolysis parameters on the kinetics of composite deposition, while changes of intensity of peaks in the anodic branch as well as changes of the quartz crystal resonator frequency changes clearly indicated the significant influence of several electrolysis parameters on the kinetics of composite synthesis. The obtained results indicated that both the presence of the magnetic field as well as $\mathrm{TiO}_{2}$ particle concentration influenced the increase of the composite deposition rate.
Figure 6 presents the results of WD-XRF analyses performed for the synthesized coatings. Coatings synthesized without the presence of a magnetic field contained a higher $\mathrm{TiO}_{2}$ content than that deposited at $B>0 T$. $\mathrm{TiO}_{2}$ content in composites synthesized at $B=0 T$ ranged from 0.9 wt. pct $(E=-1.4 \mathrm{~V}, 2.5 \mathrm{~g} / \mathrm{L}$ $\left.\mathrm{TiO}_{2}\right)$ to 1.62 wt. pct $\left(E=-1.2 \mathrm{~V}, 10 \mathrm{~g} / \mathrm{L} \mathrm{TiO}_{2}\right)$. A decrease of electrode potential from $E=-1.2 \mathrm{~V}$ to $E=-1.4 \mathrm{~V}$ resulted in a decrease of $\mathrm{TiO}_{2}$ content in coatings by 0.2 to 0.3 wt. pct. A positive effect of $\mathrm{TiO}_{2}$ concentration in the electrolyte on its content in deposits was observed independent of the working electrode potential value. In the presence of a magnetic field, the effect of the potential decrease on $\mathrm{TiO}_{2}$ content in the coatings was the reverse to that observed at $B=0 \mathrm{~T}$. Independent of $\mathrm{TiO}_{2}$ concentration in the electrolyte, a decrease of the electrode potential resulted in the increasing $\mathrm{TiO}_{2}$ content in cathodic deposits. At $B=1 T$, the $\mathrm{TiO}_{2}$ content in coatings ranged from 0.31 wt. pct $\left(E=-1.3 \mathrm{~V}, 2.5 \mathrm{~g} / \mathrm{L} \mathrm{TiO}_{2}\right)$ to 2.15 wt. pct $\left(E=-1.4 \mathrm{~V}, 10 \mathrm{~g} / \mathrm{L} \mathrm{TiO}_{2}\right)$. The influence of the working electrode potential on the increase of $\mathrm{TiO}_{2}$ content in deposits is more pronounced with the increase of its concentration in the electrolyte. The effect of the magnetic field on incorporation of $\mathrm{TiO}_{2}$ into the $\mathrm{Ni}$ matrix is also clearly visible. The presence of the magnetic field caused an increase of $\mathrm{TiO}_{2}$ content in comparison with coatings synthesized at $B=0 T$ only for materials synthesized at $E=-1.4 \mathrm{~V}$ from electrolytes containing $>2.5 \mathrm{~g} / \mathrm{L} \mathrm{TiO}_{2}$. For $E=-1.3 \mathrm{~V}$, an increase of $\mathrm{TiO}_{2}$ content was observed only for electrolyte containing $10 \mathrm{~g} / \mathrm{L} \mathrm{TiO}_{2}$. In the remaining cases, the presence of magnetic field caused a decrease of $\mathrm{TiO}_{2}$ in the synthesized coatings.

Cathodic current efficiency was analyzed based on charge quantity corresponding to electrolysis and electrode mass changes related to coating formation. Figure 7 presents current-time transient curves recorded

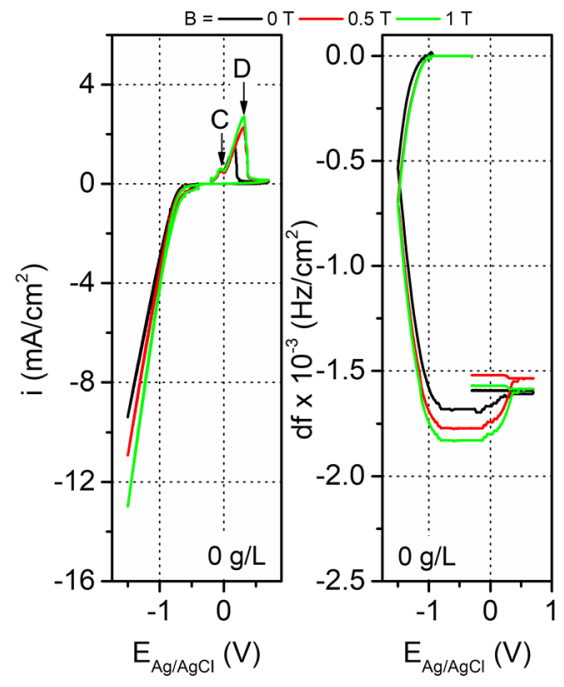

(a)

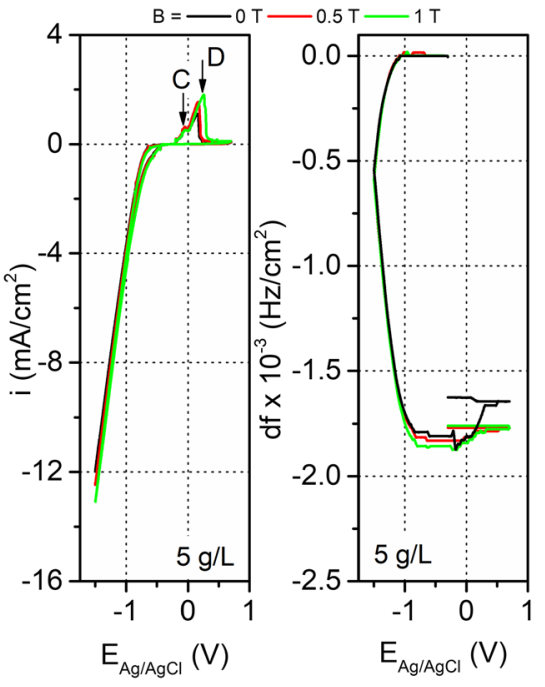

(b)

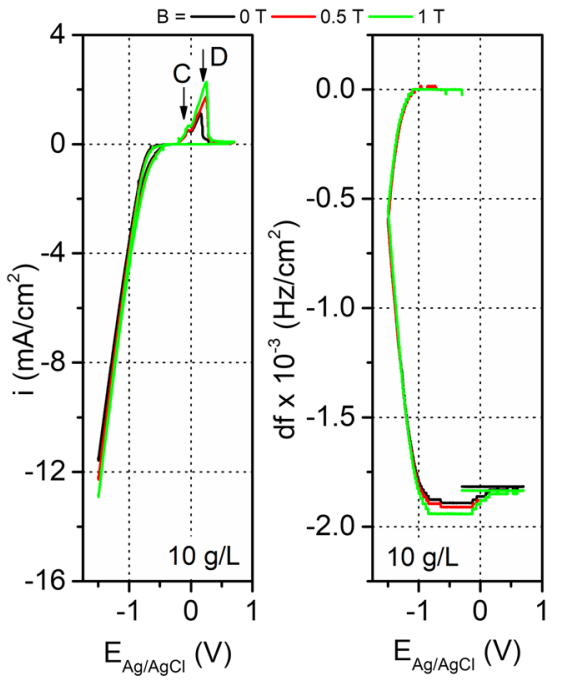

(c)

Fig. 5- CVs with corresponding quartz crystal oscillations frequency changes registered in electrolytes of different concentrations of $\mathrm{TiO}_{2}$ particles: $(a) 0 \mathrm{~g} / \mathrm{L},(b) 5 \mathrm{~g} / \mathrm{L},(c) 10 \mathrm{~g} / \mathrm{L}$; and $B$ values $(B=0,0.5,1 T)(v=10 \mathrm{mV} / \mathrm{s})$. 


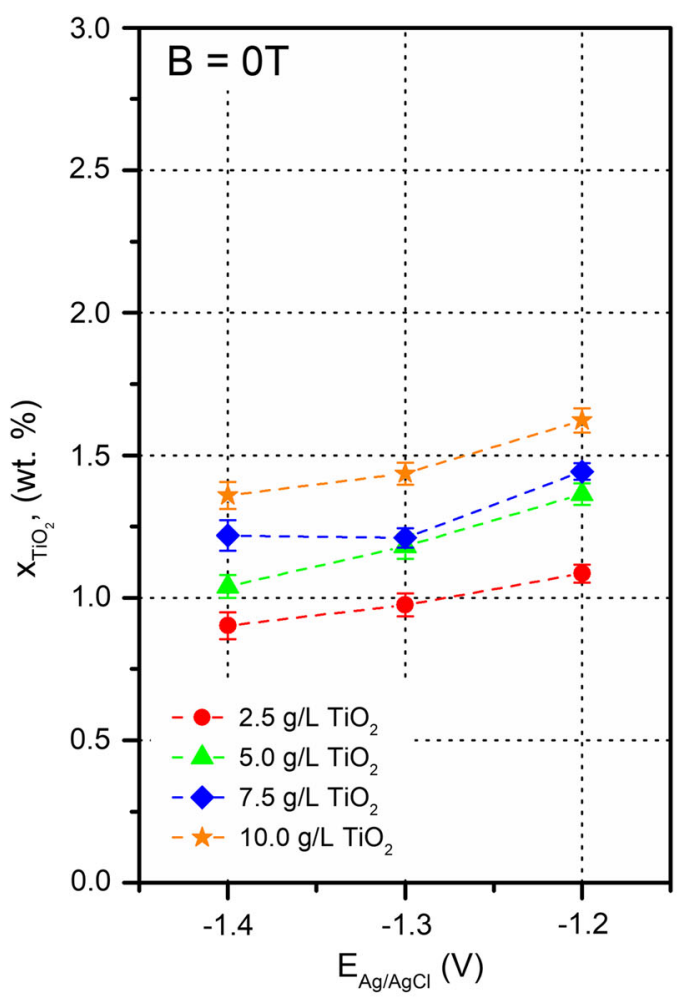

(a)

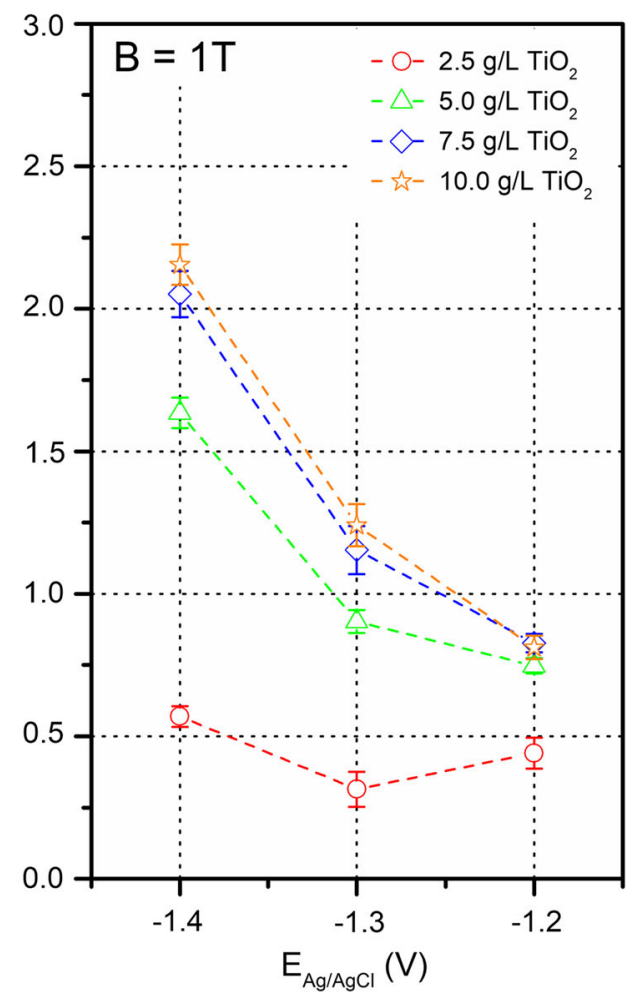

(b)

Fig. 6- $\mathrm{TiO}_{2}$ contents in $\mathrm{Ni}-\mathrm{TiO}_{2}$ composite coatings synthesized in $\mathrm{Ni}^{2+}-\mathrm{Ac}^{-}-\mathrm{H}_{2} \mathrm{O}-\mathrm{TiO}_{2}$ system: $(a)$ without external magnetic field, $(b)$ in the presence of external magnetic field of $B=1 \mathrm{~T}$.

in the $\mathrm{Ni}^{2+}-\mathrm{Ac}^{-}-\mathrm{H}_{2} \mathrm{O}-\mathrm{TiO}_{2}$ system. Independent of the magnetic field configuration, the decrease of electrode potential resulted in an increase of the quantity of charge related to electrode processes. The exception is the coating synthesized at $E=-1.4 \mathrm{~V}$, where an increase of $\mathrm{TiO}_{2}$ concentration in the electrolyte resulted in a decrease of charge quantity by $1 \mathrm{C}$, indicated by the reduction of the rate of electrode reactions. In the case of current-time transient curves recorded in the presence of the magnetic field, an increase of cathodic current density was noticed (Figure 7(b)). Changes of charge related to electrode reactions amounted to $8.3 \mathrm{C}$ caused by the presence of the magnetic field in the case of $\mathrm{Ni}$ layers were most visible at $E=-1.3 \mathrm{~V}$. In the case of composite layers, the influence of the magnetic field was the most significant for electrolyte containing $2.5 \mathrm{~g} / \mathrm{L}$ $\mathrm{TiO}_{2}$ at $E=-1.3 \mathrm{~V}$, where changes in charge quantity amounted to $15.5 \mathrm{C}$. The course of recorded chronoamperometric indicated an increased kinetics of electrode reactions under magnetic field, and this is coherent with previously described results of DPV, CV, and electrogravimetric studies.

Table II presents values of real charge determined based on the electrode mass changes and charge determined on current-time transient curves visible in Figure 7. In each case, the presence of the magnetic field resulted in an increase of electrolysis efficiency. The highest increase of cathodic efficiency by 20.4 pct caused by the presence of the magnetic field was observed for a composite coating synthesized using electrolyte containing $10 \mathrm{~g} / \mathrm{L} \mathrm{TiO}_{2}$ at $E=-1.4 \mathrm{~V}$, whereas the lowest, amounting to $2.5 \mathrm{pct}$, was observed for $0 \mathrm{~g} / \mathrm{L}$ $\mathrm{TiO}_{2}$ at $E=-1.4 \mathrm{~V}$. Regardless of the magnetic field configuration, a clear effect of working electrode potential as well as $\mathrm{TiO}_{2}$ concentration in the electrolyte on current efficiency was not observed. An increase of efficiency in the presence of magnetic field results from the influence of MHD effect on kinetics of transport of electrochemically active $\left[\mathrm{Ni}\left(\mathrm{CH}_{3} \mathrm{COO}\right)\right]^{+}$and $\left[\mathrm{Ni}\left(\mathrm{H}_{2} \mathrm{O}\right)_{6}\right]^{2+}$ complexes toward the electrode surface which in turn limits the concurrent reaction of $\mathrm{H}^{+}$ions reduction resulting in hydrogen gas formation.

In Figure 8, there are visible XRD spectra recorded for samples deposited from electrolytes containing acetic nickel complexes. Although the $\mathrm{TiO}_{2}$ content in all coatings deposited at $B=0 T$ exceeded 0.9 wt. pct in $\mathrm{XRD}$, spectra peaks coming from the anatase and rutile $\mathrm{TiO}_{2}$ phase were not visible. It was observed that regardless of applied electrolysis potential as well as $\mathrm{TiO}_{2}$ concentration, precipitation of nickel hydroxide takes place. ${ }^{[40]}$ In addition, peaks coming from the $\mathrm{Ni}_{1-x} \mathrm{H}_{x}{ }^{[41,42]}$ phase show the presence of hydrogen absorbed into the nickel crystal lattice. Hydrogen absorption was also confirmed by results of voltammetric and electrogravimetric tests. In XRD spectra recorded for coatings synthesized in the presence of the magnetic field, despite the $\mathrm{TiO}_{2}$ content in coatings being higher $\left(>2.5 \mathrm{~g} / \mathrm{L} \mathrm{TiO}_{2}, E=-1.4 \mathrm{~V}\right)$, peaks coming from the $\mathrm{TiO}_{2}$ phase also were not observed. In that case, only peaks coming from the $\mathrm{Ni}_{1-x} \mathrm{H}_{x}{ }^{[41,42]}$ and 


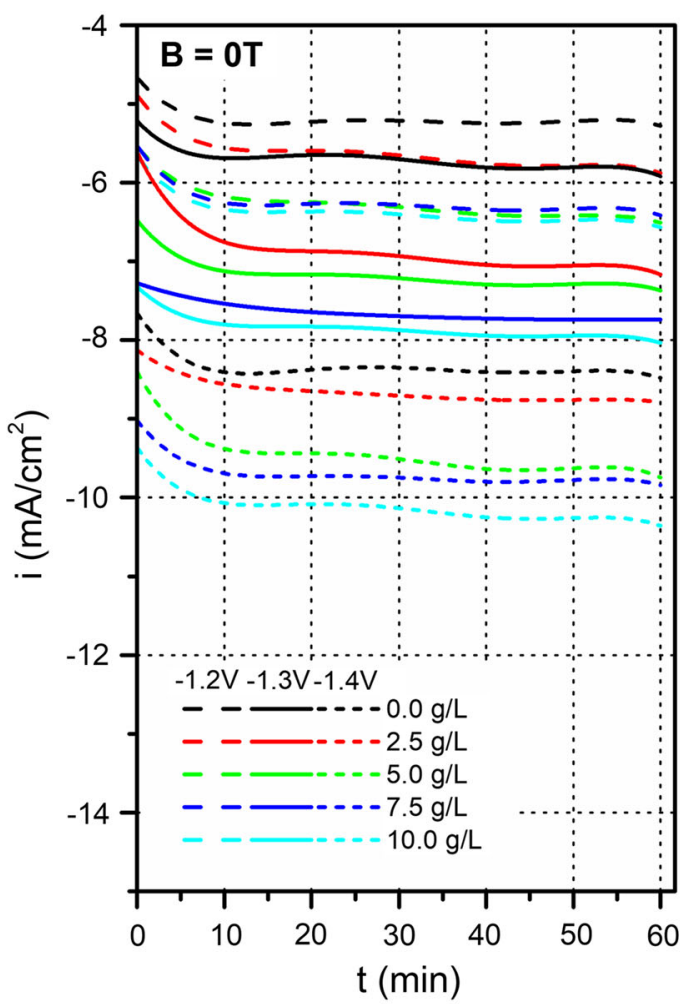

(a)

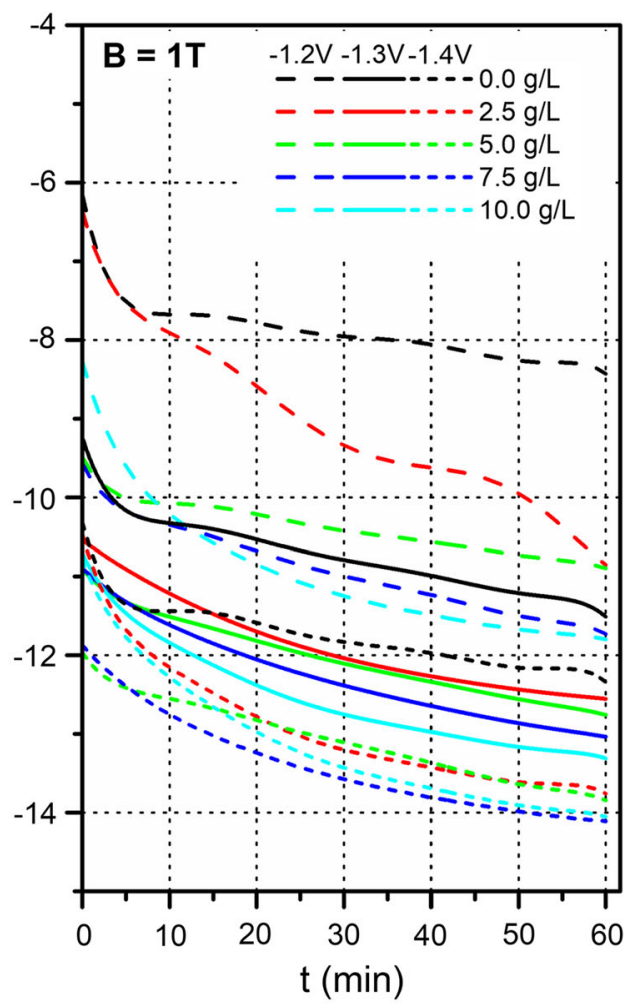

(b)

Fig. 7-Current-time transient curves recorded during electrolysis performed $(a)$ without external magnetic field, $(b)$ in the presence of external magnetic field of $B=1 T$.

Table II. Charge Estimated Based on Current-Time Transient Curves and Based on Changes of the Mass Changes of Working Electrode and Current Efficiency of Electrolysis Under Several Conditions

\begin{tabular}{|c|c|c|c|c|c|c|c|}
\hline \multirow[b]{2}{*}{$\mathrm{TiO}_{2}(\mathrm{~g} / \mathrm{L})$} & \multirow[b]{2}{*}{$E(\mathrm{~V})$} & \multicolumn{3}{|c|}{$\mathrm{B}=0 T$} & \multicolumn{3}{|c|}{$\mathrm{B}=1 T$} \\
\hline & & $q_{\mathrm{ChA}}(\mathrm{C})$ & $q_{\mathrm{dm}}(\mathrm{C})$ & $\eta_{\mathrm{Ni}}(\mathrm{Pct})$ & $q_{\mathrm{ChA}}(\mathrm{C})$ & $q_{\mathrm{dm}}(\mathrm{C})$ & $\eta_{\mathrm{Ni}}(\mathrm{Pct})$ \\
\hline \multirow[t]{3}{*}{0} & -1.2 & 18.7 & 4.0 & 21.1 & 28.4 & 8.2 & 28.9 \\
\hline & -1.3 & 20.6 & 4.9 & 24.0 & 38.7 & 12.5 & 32.3 \\
\hline & -1.4 & 30.1 & 9.5 & 31.7 & 42.4 & 14.5 & 34.2 \\
\hline \multirow[t]{3}{*}{2.5} & -1.2 & 20.3 & 4.5 & 22.3 & 32.5 & 11.1 & 34.1 \\
\hline & -1.3 & 24.7 & 5.8 & 23.6 & 42.8 & 16.7 & 39.1 \\
\hline & -1.4 & 31.2 & 7.5 & 23.9 & 46.5 & 16.7 & 35.9 \\
\hline \multirow[t]{3}{*}{5.0} & -1.2 & 22.6 & 4.9 & 21.5 & 37.4 & 14.0 & 37.4 \\
\hline & -1.3 & 25.9 & 6.5 & 25.1 & 43.3 & 16.3 & 37.6 \\
\hline & -1.4 & 34.1 & 7.8 & 22.9 & 47.1 & 17.5 & 37.2 \\
\hline \multirow[t]{3}{*}{7.5} & -1.2 & 22.5 & 5.2 & 23.0 & 39.3 & 15.0 & 38.2 \\
\hline & -1.3 & 27.5 & 6.2 & 22.4 & 44.2 & 15.8 & 35.8 \\
\hline & -1.4 & 35.0 & 8.5 & 24.2 & 48.3 & 17.7 & 36.7 \\
\hline \multirow[t]{3}{*}{10} & -1.2 & 23.0 & 5.5 & 24.1 & 39.5 & 16.0 & 40.5 \\
\hline & -1.3 & 28.3 & 6.8 & 24.2 & 45.2 & 19.8 & 43.8 \\
\hline & -1.4 & 36.5 & 9.4 & 25.9 & 47.3 & 21.9 & 46.3 \\
\hline
\end{tabular}

$\mathrm{Ni}_{1-x-y} \mathrm{O}_{x} \mathrm{H}_{y}{ }^{[40]}$ phases were observed, as was observed in case of coatings deposited at $B=0 T$. The recorded spectra reveal the clear influence of the magnetic field on Ni matrix crystallization kinetics, which was indicated by an increase of the intensity of (111) and (200) peaks coming from the Ni metal phase. ${ }^{[43]}$

XPS measurements were performed for samples of the highest concentrations of $\mathrm{TiO}_{2}$ deposited at $B=0 T$ and $B=1 T$. In Table III, electrolysis parameters corresponding to the analyzed coatings as well as results of surface quantitative analysis performed based on recorded XPS spectra shown in Figure 9 are presented. In Figure 9(a), there are visible $2 p$ spectral lines of doublet structure with the main line centered at $458.7 \mathrm{eV}$, indicating the presence of $\mathrm{Ti}^{4+}$ states due to the presence of $\mathrm{TiO}_{2}{ }^{[44]}$ (Figure 9(a)). In the coating 


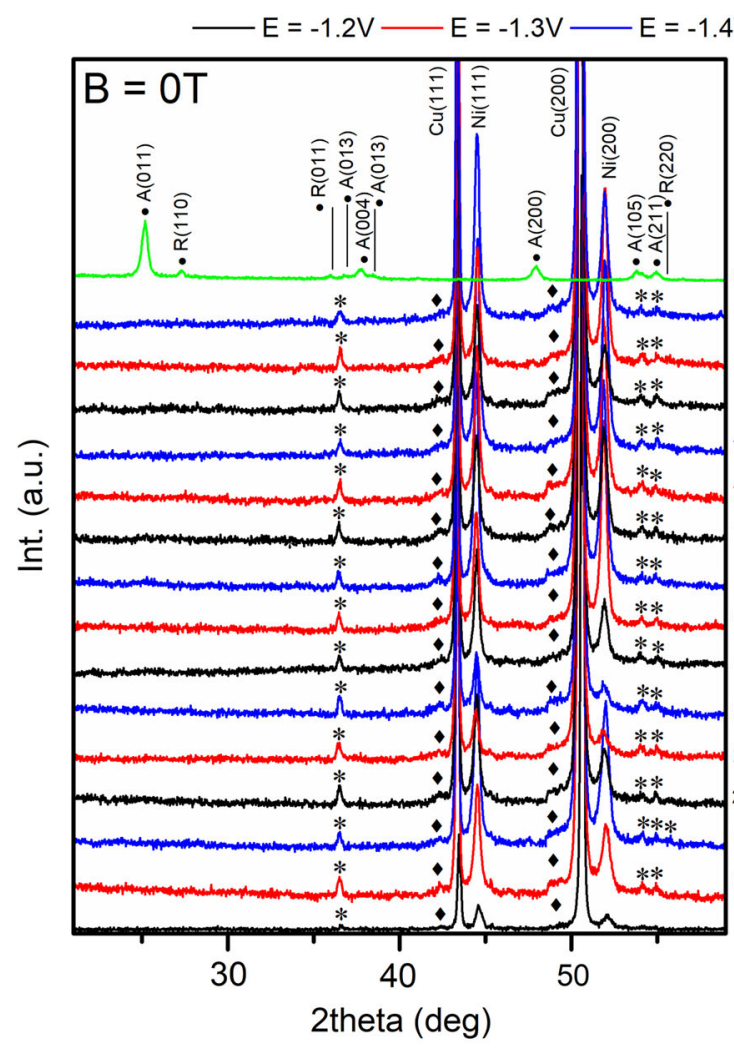

(a)

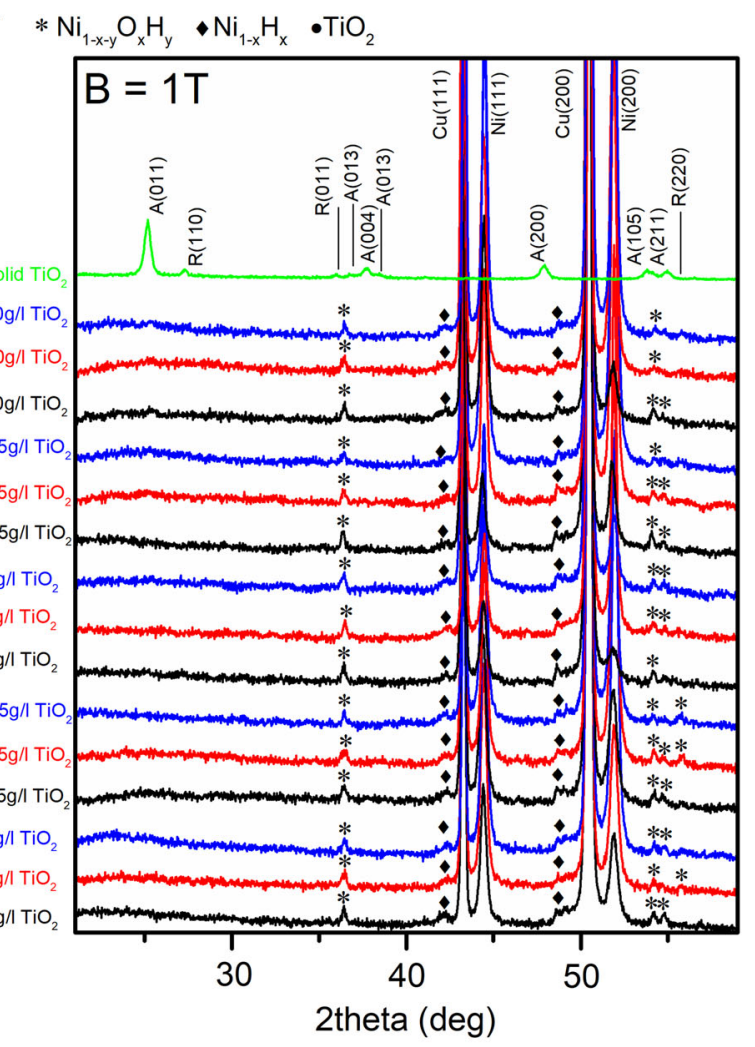

(b)

Fig. 8-XRD spectra recorded for coatings synthesized in $\mathrm{Ni}^{2+}-\mathrm{Ac}^{-}-\mathrm{H}_{2} \mathrm{O}$ and $\mathrm{Ni}^{2+}-\mathrm{Ac}^{-}-\mathrm{H}_{2} \mathrm{O}-\mathrm{TiO}_{2}$ systems: (a) without magnetic field, $(b)$ in the presence of magnetic field of $B=1 T$.

Table III. Surface Elemental Composition (Atomic Percent) Based on XPS Spectra

\begin{tabular}{lccccccc}
\hline System & $\mathrm{TiO}_{2}(\mathrm{~g} / \mathrm{L})$ & $E(\mathrm{~V})$ & $B(T)$ & $\mathrm{C}$ & $\mathrm{O}$ & $\mathrm{Ti}$ & $\mathrm{Ni}$ \\
\hline $\mathrm{Ni}^{2+}-\mathrm{Ac}^{-}-\mathrm{H}_{2} \mathrm{O}-\mathrm{TiO}_{2}$ & 10 & -1.4 & 0 & 42.2 & 35.5 & 2.3 & 20.0 \\
& & & 1 & 35.8 & 31.8 & 5.2 & 27.2 \\
\hline
\end{tabular}

surfaces, large amounts of $\mathrm{C}$ (ranging from 35.8 to 52.2 at. pct) and oxygen (from 31.8 to 35.5 at. pct) were detected. The quantities of $\mathrm{C}$ and $\mathrm{O}$ in the coating surfaces were higher for the sample deposited at $B=0$ $T$ by a few percent. The surface concentrations of $\mathrm{TiO}_{2}$ at the electrode surface were found to be 2.3 and 5.2 at. pct for $B=0 \quad T$ and $1 T$, respectively. It was observed that the surface concentrations of $\mathrm{TiO}_{2}$ and $\mathrm{Ni}$ were significantly higher for coatings deposited in the presence of the magnetic field. Significant quantities of carbon and oxygen at the coating surfaces are probably related to the presence of compounds adsorbed from atmospheric air and species coming from the electrolyte.

Figure 9 presents XPS spectra recorded for the analyzed coatings recorded in the Ti $2 p$ (a) and Ni $2 p$ (b) regions. The presence of magnetic field resulted in significant increases of intensity of $\mathrm{Ti} 2 p_{3 / 2}$ and $\mathrm{Ti} 2 p_{1 / 2}$ peaks related to the increase of $\mathrm{TiO}_{2}$ content at the coating's surface by 2.9 at. pct. In the $\mathrm{Ni} 2 p$ region, an increase in the peak intensity caused by the presence of the magnetic field related to an increase of $\mathrm{Ni}$ concentration by 7.2 at. pct was observed. For coatings deposited in the presence of magnetic field, decreases of oxygen and carbon concentrations by 3.7 and 6.4 at. pct, were observed, respectively (Table III). XPS and WD-XRF results indicated that $\mathrm{TiO}_{2}$ content regardless of the magnetic field configuration was higher in the bulk material by 0.68 at. pct for $B=0 T$ and by 3.05 at. pct for $B=1 T$ than that at the coating surfaces.

Figure 10 presents morphologies of composites synthesized in the $\mathrm{Ni}^{2+}-\mathrm{Ac}^{-}-\mathrm{H}_{2} \mathrm{O}-\mathrm{TiO}_{2}$ system. Coatings were synthesized at potentials of $E=-1.2 \mathrm{~V}$ and $E=-1.4 \mathrm{~V}$ from electrolytes of $\mathrm{TiO}_{2}$ concentrations of 0 and $10 \mathrm{~g} / \mathrm{L}$. Regardless of electrolysis conditions at the coating surface, there are visible pores indicating places corresponding to a localized hydrogen evolution reaction (HER). Observations also reveal parallel traces indicating the direction of the movement of desorbing hydrogen bubbles. Due to the low value of $\mathrm{pH}$, the rate of reactions resulting in the formation of hydrogen bubbles was relatively high. Traces are most visible in 


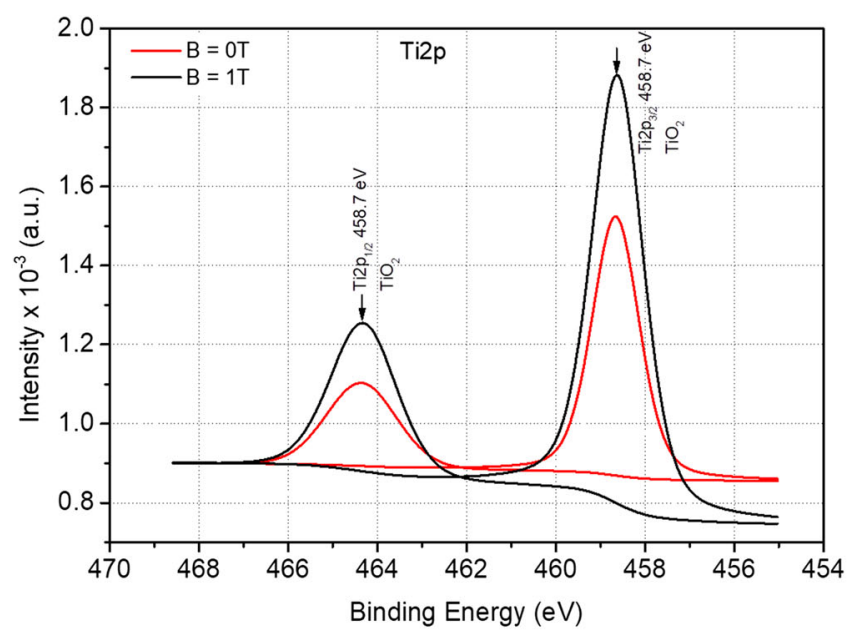

(a)

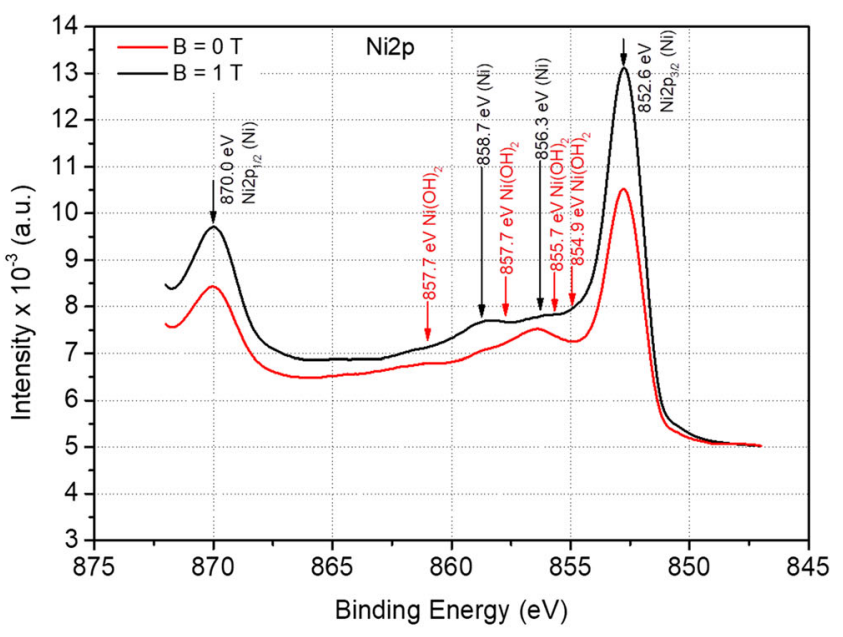

(b)

Fig. 9-XPS spectra recorded in Ti $2 p(a)$ and Ni $2 p(b)$ regions for coatings synthesized in the $\mathrm{Ni}^{2+}-\mathrm{Ac}^{-}-\mathrm{H}_{2} \mathrm{O}-\mathrm{TiO}_{2}$ system.

the case of coatings of the lowest surface roughness. 3D structures present at the coating surfaces caused changes in the direction of bubble movement protecting the surface from trace formation. Layers deposited from $\mathrm{TiO}_{2}$-free electrolytes exhibit the lowest surface roughness regardless of the magnetic field configuration. Observations also indicated the influence of the magnetic field on the elimination of the quantity of traces formed by desorbing bubbles at the electrode surface. At $E=-1.2$, the presence of the magnetic field resulted in the total decay of traces. Differences were observed in the surface morphology of coatings deposited in the presence of magnetic field resulting from additional stirring effect arising from MHD effect.

Figure 11 presents the results of photoelectrochemical studies indicating the presence of $\mathrm{TiO}_{2}$ in the deposited coatings. The analyzed coatings were deposited at $E=-1.2 \mathrm{~V}$ for $B=0 T$ and at $E=-1.4 \mathrm{~V}$ for $B=1 T$. The observed intensity of pulses was ca. $5 \mu \mathrm{A} /$ $\mathrm{cm}^{2}$. The increase of $\mathrm{TiO}_{2}$ concentration by $0.53 \mathrm{wt}$. pct resulted in the increase of photocurrent pulse height of $0.6 \mu \mathrm{A} / \mathrm{cm}^{2}$. The observed changes in the generated photocurrent related to changes in $\mathrm{TiO}_{2}$ concentration were very insignificant. The cathodic characteristics of the generated photocurrent in the presence of dissolved oxygen suggest that the incorporated $\mathrm{TiO}_{2}$ is strongly defected. Registered chronoamperograms also indicated different levels of current densities under dark conditions showing the positive influence of the presence of $\mathrm{TiO}_{2}$ on the kinetics of reactions related to HER.

\section{CONCLUSIONS}

The changes of cathodic current densities observed in DPV curves as well as the determined diffusion coefficients indicated the significant influence of the magnetic field on the kinetics of transport of species to the electrode surface. The strong effect of the magnetic field on the kinetics of processes accompanying the synthesis of $\mathrm{Ni}-\mathrm{TiO}_{2}$ composites was also indicated by the quantity of the charge related to the synthesis of coatings under several conditions as well as by the slope of the recorded electrogravimetric curves. The changes of the slope of electrogravimetric curves resulting from changes of $\mathrm{B}$ value are a clear evidence regarding the influence of MHD effect on mass transport processes. It should be noticed that under the magnetic field, the effect of decreased electrode potential on $\mathrm{TiO}_{2}$ content in deposits was quite opposite relative to those observed at $B=0 T$. The presence of the magnetic field of $B=1$ $T$ regardless of electrolysis conditions resulted in increases of current efficiency as well as cathodic current density as indicated by current-time transient curves in almost all cases at $B=0 T$, and a decrease of electrode potential value resulted in a slight increase of current efficiency. The positive effect of potential changes on current efficiency was observed only in the $\mathrm{Ni}^{2+}-\mathrm{Ac}^{-}-\mathrm{H}_{2} \mathrm{O}$ and $\mathrm{Ni}^{2+}-\mathrm{Ac}^{-}-\mathrm{H}_{2} \mathrm{O}-\mathrm{TiO}_{2}$ systems containing $10 \mathrm{~g} / \mathrm{L} \mathrm{TiO}$. The above facts indicate the very complex character of the processes responsible for the formation of composites in an acetate-based system. The shape of current-time transient curves as well as cyclic voltammograms indicated that the synthesis is accompanied by HER. Electrodeposited composite $\mathrm{Ni}-\mathrm{TiO}_{2}$ coatings contained up to 2.15 wt. pet $\mathrm{TiO}_{2}$. The efficiency of Ni matrix electrodeposition ranged from 21.1 to 31.7 pct for $B=0 T$ and from 28.9 to 34.2 pct for $B=1 T$. The XRD and XPS results indicated the presence of nickel hydroxides and nickel hydrides at the surfaces of synthesized coatings. The possibilities of its formation were previously indicated by cyclic voltammograms. Pores as well as parallel traces at the coating surfaces also indicated that the synthesis process is accompanied by HER. SEM observations also confirmed that surface morphology is strongly dependent on electrolysis conditions. The presence of $\mathrm{TiO}_{2}$ was also indicated by the observed photocurrents generated by materials under illumination at $\lambda=375 \mathrm{~nm}$. 


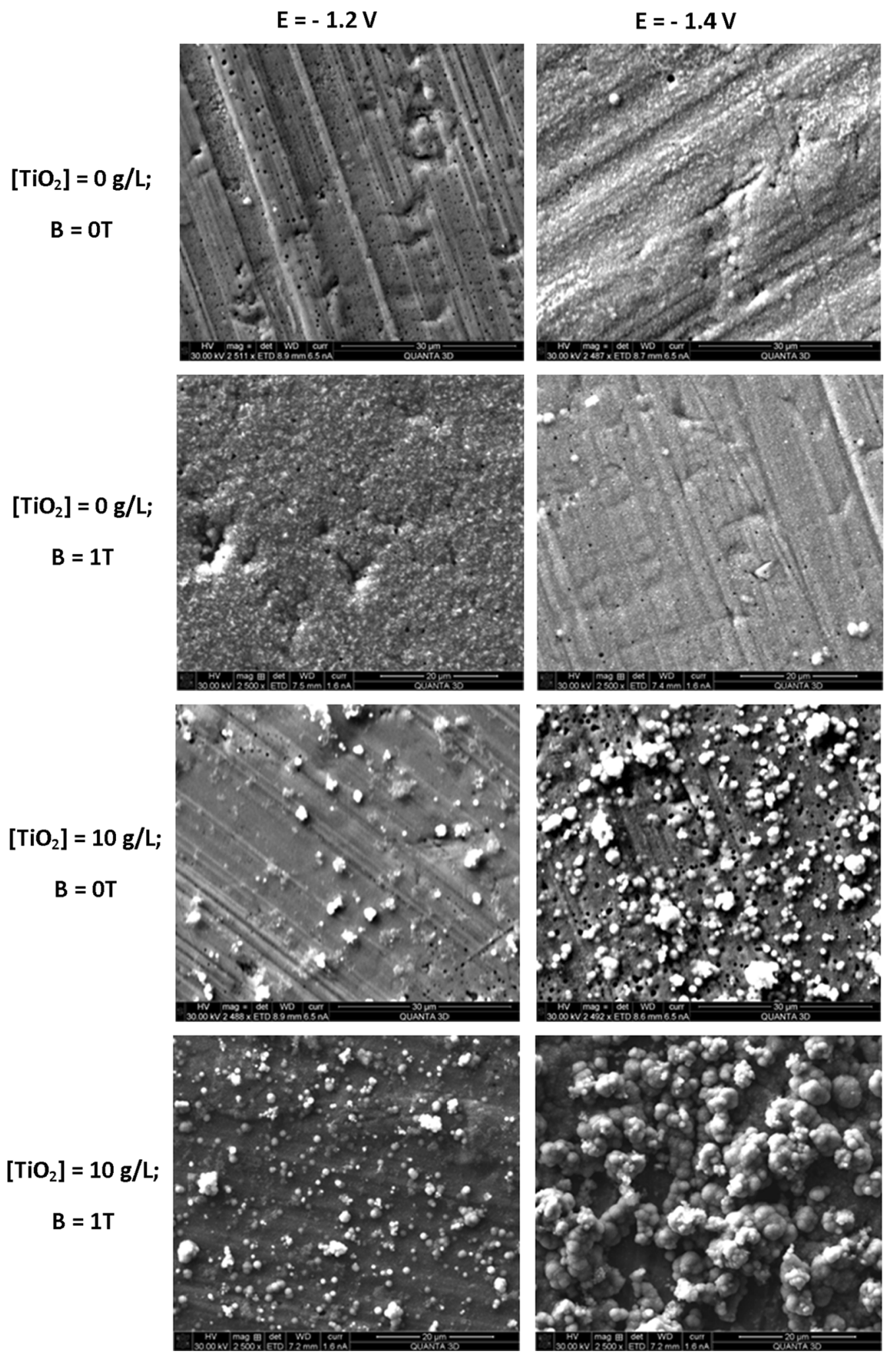

Fig. 10-Morphologies of $\mathrm{Ni}$ and $\mathrm{Ni}^{-\mathrm{TiO}_{2}}(10 \mathrm{~g} / \mathrm{L} \mathrm{TiO} 2)$ coatings deposited at $E=-1.2 \mathrm{~V}$ and $E=-1.4 \mathrm{~V}$ in magnetic field of $B=0 T$ and $B=1 T$.

Performed electrochemical studies as well as the results of coatings' characterization demonstrated that the application of magnetic field may be a very useful method enabling modification of the properties of synthesized materials due to its influence on kinetics of processes taking place at the electrode surface during electrodeposition process. 


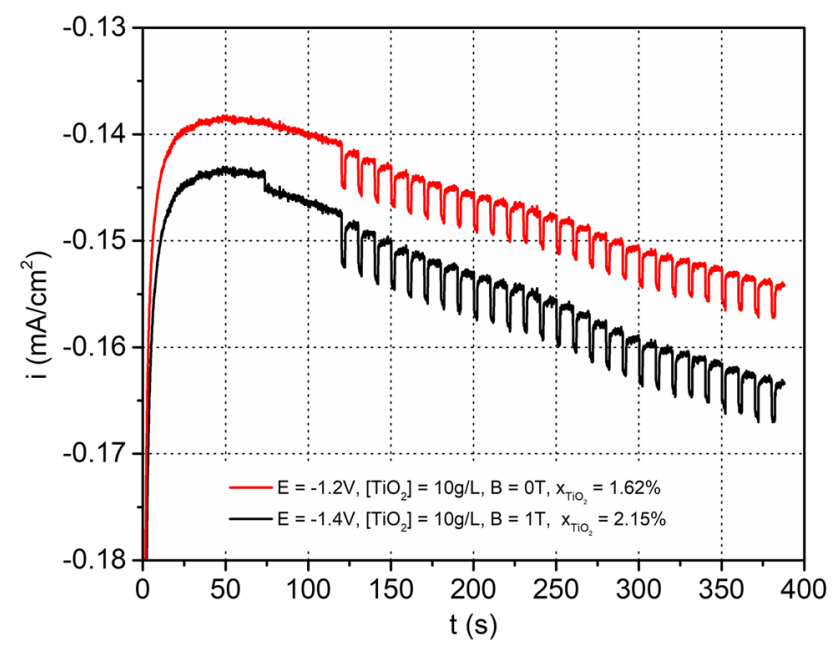

Fig. 11-Photocurrent action characteristics of $\mathrm{Ni}-\mathrm{TiO}_{2}$ composites electrodeposited at $E=-1.3 \mathrm{~V}$ from electrolyte containing $10 \mathrm{~g} / \mathrm{L}$ of $\mathrm{TiO}_{2}\left(E=-0.5 \mathrm{~V}, 0.1 \mathrm{~N} \mathrm{KNO}_{3}, \lambda=375 \mathrm{~nm}, \mathrm{P}=140 \mathrm{~mW}\right.$, Pulse length: $2.5 \mathrm{~s}$, Pulse interruption: $2.5 \mathrm{~s}$ ).

\section{ACKNOWLEDGMENTS}

This study was supported by Polish Ministry of Science and Higher Education under grant IP2015/049974 as well as by Polish National Center of Science under grant 2017/26/D/ST8/00508. K. Mech would like to thank M. Marzec for his help in the frame of XPS measurements and P. Zabinski for enabling WD-XRF measurements.

\section{OPEN ACCESS}

This article is distributed under the terms of the Creative Commons Attribution 4.0 International License (http://creativecommons.org/licenses/by/4.0/), which permits unrestricted use, distribution, and reproduction in any medium, provided you give appropriate credit to the original author(s) and the source, provide a link to the Creative Commons license, and indicate if changes were made.

\section{REFERENCES}

1. G. Kumar, E. Nikolla, S. Linic, J.W. Medlin, and M.J. Janik: ACS Catal., 2018, vol. 8 (4), pp. 3202-08.

2. A.A. Ismail and D.W. Bahnemann: Sol. Energy Mater. Sol. C., 2014, vol. 128 , pp. 85-101.

3. K. Pilarczyk, K. Lewandowska, K. Mech, M. Kawa, M. Gajewska, B. Barszcz, A. Bogucki, A. Podborska, and K. Szaciłowski: $J$. Mater. Chem. C, 2017, vol. 5 (9), pp. 2415-24.

4. J. Mech, K. Mech, and K. Szaciłowski: J. Mater. Chem. C, 2015, vol. 3 (16), pp. 4148-55.

5. K. Mech, J.P. Chopart, M. Wróbel, P. Zabiński, and K. Szaciłowski: J. Electrochem. Soc., 2017, vol. 164 (9), pp. D613-20.

6. K. Mech, M. Wróbel, M. Wojnicki, J. Mech-Piskorz, P. Żabiński, and R. Kowalik: Appl. Surf. Sci., 2016, vol. 388, pp. 809-16.
7. K. Mech, P. Zabiński, R. Kowalik, T. Tokarski, and K. Fitzner: $J$. Appl. Electrochem., 2014, vol. 44 (1), pp. 97-103.

8. K. Mech, P. Zabinski, R. Kowalik, and M. Wojnicki: Surf. Coat. Technol., 2014, vol. 258, pp. 72-77.

9. K. Mech, P. Zabiński, M. Mucha, and R. Kowalik: Arch. Metall. Mater., 2013, vol. 58 (1), pp. 227-29.

10. P. Zabiński, K. Mech, and R. Kowalik: Arch. Metall. Mat., 2012, vol. 57 (1), pp. 127-33.

11. F. Kuttassery, D. Yamamoto, S. Mathew, S.N. Remello, A. Thomas, Y. Nabetani, A. Iwase, A. Kudo, H. Tachibana, and H. Inoue: J. Photochem. Photobiol. A, 2018, vol. 358, pp. 386-94.

12. L. Wang, C.S. Tsang, W. Liu, X. Zhang, K. Zhang, E. Ha, W.M. Kwok, J.H. Park, L.Y. Suk Lee, and K.Y. Wong: J. Mater. Chem. A, 2019, vol. 7 (1), pp. 221-27.

13. L. Benea and A.I. Pavlov: Optoelectron. Adv. Mater., 2013, vol. 7 (11-12), pp. 895-99.

14. T. Xu, S. Wang, L. Li, and X. Liu: Appl. Catal. A, 2019, vol. 575, pp. $132-41$.

15. H. Wang, H. Liu, S. Wang, L. Li, and X. Liu: Appl. Catal. B, 2018, vol. 224, pp. 341-49.

16. T. Xu, X. Liu, S. Wang, and L. Li: Nano-Micro Lett., 2019, vol. 11 (1), p. 37.

17. J.C. Durán-Alvarez, R. Zanella, and S. Oros-Ruiz: Heterogeneous Gold Catalysts and Catalysis, The Royal Society of Chemistry, London, 2014, pp. 155-228.

18. M. Zhou, N.R. De Tacconi, and K. Rajeshwar: J. Electroanal. Chem., 1997, vol. 421 (1-2), pp. 111-20.

19. N.R. De Tacconi, M. Mrkic, and K. Rajeshwar: Langmuir, 2000, vol. 16 (22), pp. 8426-31.

20. N. Shimoda, D. Shoji, K. Tani, M. Fujiwara, K. Urasaki, R. Kikuchi, and S. Satokawa: Appl. Catal. B, 2015, vol. 174, pp. 486-95.

21. X.C. Meng, H.Y. Cheng, S. Fujita, Y.F. Hao, Y.J. Shang, Y.C. Yu, S.X. Cai, F.Y. Zhao, and M. Arai: J. Catal., 2010, vol. 269 (1), pp. $131-39$.

22. R.M. Mohamed and E.S. Aazam: Chin. J. Catal., 2012, vol. 33 (2), pp. $247-53$.

23. W.J. Ong, M.M. Gui, S.P. Chai, and A.R. Mohamed: RSC Adv., 2013, vol. 3 (14), pp. 4505-09.

24. S. Mohajeri, A. Dolati, and M. Ghorbani: Surf. Coat. Technol., 2015, vol. 262, pp. 173-83.

25. D. Thiemig and A. Bund: Surf. Coat. Technol., 2008, vol. 202 (13), pp. 2976-84.

26. V. Stanković, M. Gojo, V. Grekulovic, N. Pajkić, and T. Cigula: $J$. Miner. Metall. B, 2017, vol. 53 (3), pp. 341-48.

27. P. Zabiński, K. Mech, and R. Kowalik: Electrochim. Acta, 2013, vol. 104 , pp. 542-48.

28. R. Kowalik, K. Mech, D. Kutyla, T. Tokarski, and P. Zabinski: Magnetohydrodynamics, 2015, vol. 51 (2), pp. 345-51.

29. H. Kermoune, A. Levesque, J. Douglad, R. Rehamnia, and J.P. Chopart: Ionics, 2017, vol. 23 (12), pp. 3565-70.

30. D. Li, Y. Gao, Q. Wang, G. Li, C. Wu, A.L. Daltin, and J.P. Chopart: J. Electrochem. Soc., 2016, vol. 163 (14), pp. D836-41.

31. Q. Feng, T. Li, Z. Zhang, J. Zhang, M. Liu, and J. Jin: Surf. Coat. Technol., 2007, vol. 201 (14), pp. 6247-52.

32. J.A. Koza, M. Uhlemann, A. Gebert, and L. Schultz: Electrochem. Commun., 2008, vol. 10 (9), pp. 1330-33.

33. A. Krause, C. Hamann, M. Uhlemann, A. Gebert, and L. Schultz: J. Magn. Magn. Mater., 2005, vols. 290-291, pp. 261-64.

34. I. Puigdomenech: HYDRA (Hydrochemical Equilibrium-Constant Database) and MEDUSA (Make Equilibrium Diagrams Using Sophisticated Algorithms) Programs, Royal Institute of Technology, Stockholm, 2006.

35. A.E. Martell and R.M. Smith: Critical Stability Constants, Plenum Press, New York, 1976.

36. B. Beverskog and I. Puigdomenech: Corros. Sci., 1997, vol. 39 (5), pp. 969-80.

37. N.V. Plyasunova, Y. Zhang, and M. Muhammed: Hydrometallurgy, 1998, vol. 48, pp. 43-63.

38. K. Mech: Surf. Coat. Technol., 2017, vol. 315, pp. 232-39.

39. T. Berzins and P. Delahay: J. Am. Chem. Soc., 1953, vol. 75 (3), pp. $555-59$. 
40. C. Greaves, A.M. Malsbury, and M.A. Thomas: Solid State Ionics, 1986, vols. 18-19, pp. 763-67.

41. V.E. Antonov: J. Alloy. Compd., 2002, vol. 330, pp. 110-16.

42. E.O. Wollan, J.W. Cable, and W.C. Koehler: J. Phys. Chem. Solids, 1963, vol. 24 (9), pp. 1141-43.

43. H.E. Swanson, E. Tatge, and S. United: Standard X-ray Diffraction powder patterns. Data for 54 inorganic substances, National Bureau of Standards, Washington, DC, 1953, vol. I.
44. C.D. Wagner, A.V. Naumkin, A. Kraut-Vass, J.W. Allison, C.J. Powell, J.R.J. Rumble: NIST Standard Reference Database 20, Version 3.4.

Publisher's Note Springer Nature remains neutral with regard to jurisdictional claims in published maps and institutional affiliations. 